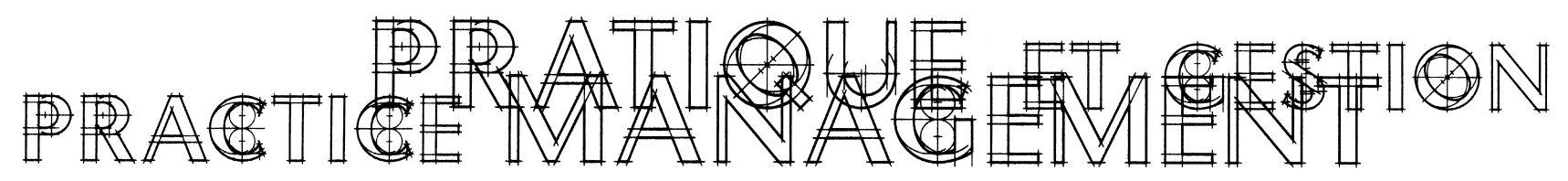

\title{
Working in the Margins
}

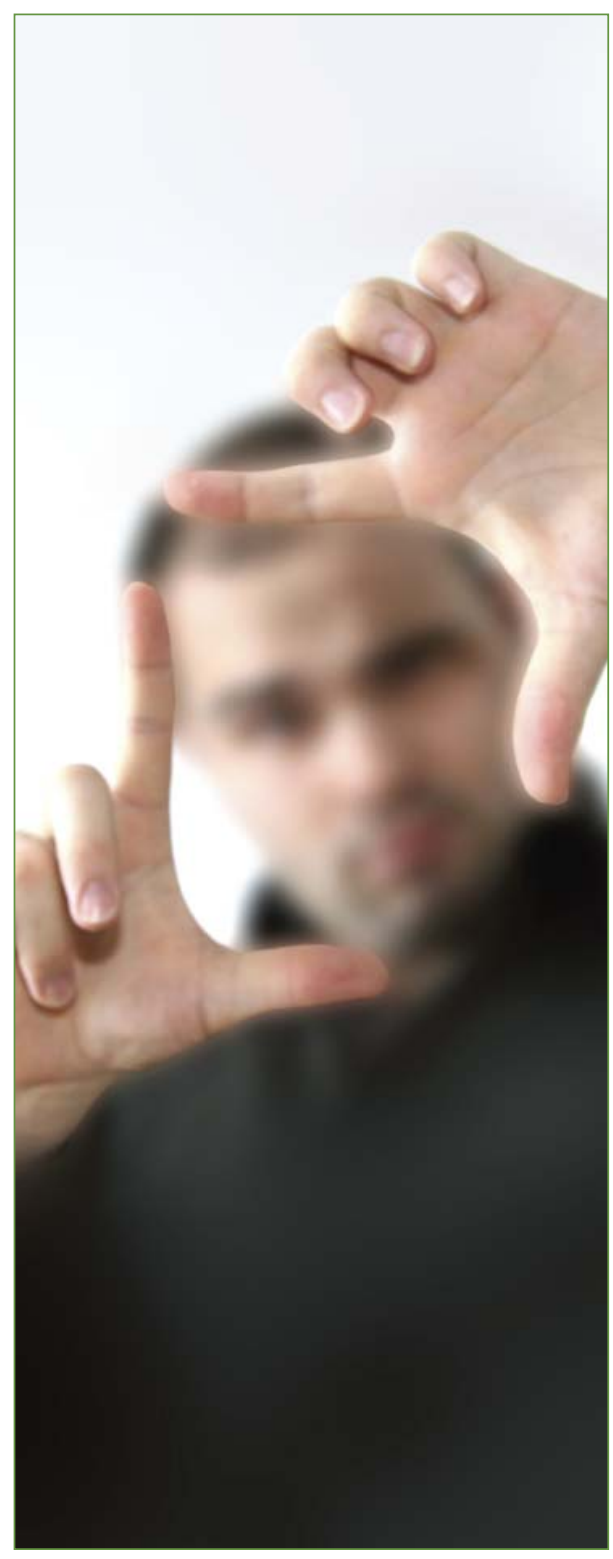

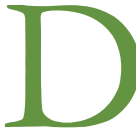

o you know that not every dollar made in your practice has the same value? The last dollars you make are worth a lot more to you than you may realize.

Let's look at a simple model for a practice that makes $\$ 300,000$ in gross revenue, has $\$ 100,000$ in expenses for goods (frames, lenses and contact lenses) and $\$ 100,000$ in general expenses leaving $\$ 100,000$ for net income.

\begin{tabular}{lll} 
Gross & $\$ 300,000$ & \\
Cost of Goods & $\$ 100,000$ & \\
Contribution Margin & $\$ 200,000$ & $67 \%$ \\
\hline & & \\
\hline Expenses & $\$ 100,000$ & \\
Net Income & $\$ 100,000$ & $33 \%$ \\
\hline
\end{tabular}

The two fixed (or nearly fixed) figures in this example are the expenses at $\$ 100,000$, and the contribution margin at $67 \%$. At first glance one might think that for every dollar made in this practice $33 \%$ of it turns into net income but that's not exactly what happens.

Before your practice can make any income it needs to reach its break-even point. Up until this stage every dollar in gross income goes to cover your expenses, and nothing is left over. To calculate this breakeven point, divide your expenses (which we are assuming are all fixed for this simple model) by the contribution margin percentage. In this example it is $\$ 100,000$ in expenses divided by $67 \%$ or $\$ 150,000$.

Here's how it would look like on your income statement.

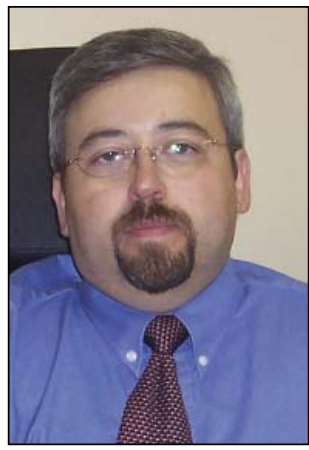

Alphonse Carew $\mathrm{BSC}, \mathrm{OD}, \mathrm{MBA}$ 


\section{PRACTICE MANAGEMENT

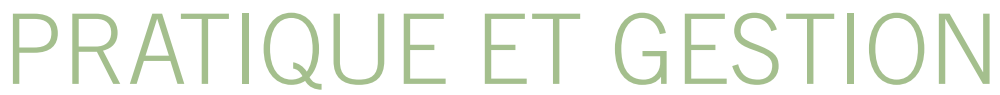

Breakeven

$\begin{array}{lll}\text { Gross } & \$ 150,000 & \\ \text { Cost of Goods } & \$ 50,000 & \\ \text { Contribution Margin } & \$ 100,000 & 67 \% \\ \text { Expenses } & \$ 100,000 & \\ \text { Net Income } & \$ 0 & 0 \%\end{array}$

Producing $\$ 150,000$ in gross revenue allows you to pay your suppliers and your expenses without anything left over. Thankfully, except for early start-up practices this typically is not a concern for most optometric practices.

Above the breakeven point, your general expenses are fully covered and the next dollars that are made only have the Cost of Goods expenses tied to them. Therefore in our example each dollar after breakeven is worth $67 \%$ in net income. By example, let's say we make $\$ 100,000$ more in gross revenue, then the net income will be $67 \%$ of this or $\$ 66,667$.

\begin{tabular}{lll} 
Gross & $\$ 250,000$ & \\
Cost of Goods & $\$ 83,333$ & \\
Contribution Margin & $\$ 166,667$ & $67 \%$ \\
\hline Expenses & $\$ 100,000$ & \\
Net Income & $\$ 66,667$ & $27 \%$ \\
\hline
\end{tabular}

You can easily see why it is beneficial to produce more and more gross income while keeping the practice's expenses the same. After the breakeven point a higher per- centage of gross becomes net income.

This is overly simplified because at some point to produce more gross revenue you will likely have to increase expenses with more staff, or a larger space, but if you can keep there increases in expenses to a minimum you can benefit greatly from higher margins on the last dollars you make.

For optometric practices, there is another twist to the story. The contribution margin of $67 \%$ in this example is not a homogeneous figure, meaning it is derived from two separate revenue streams, in that we sell goods as well as provide services. For the most part the provision of services has no "Cost of Goods" tied to it. So if you can increase the price of services, or expand the services you provide the increase in revenue falls to the bottom line at a rate of $100 \%$. Above breakeven, for every dollar you can increase your services a dollar falls to net income! If you have the ability, increasing your fees for services, or adding services can have a larger impact on the profitability of your practice than anything else.

Let go of the mindset that your practice produces an equal amount of income for each dollar it makes. The last dollars are worth far more than first ones and more importantly if you can move your gross revenue much higher past breakeven you will benefit greatly from these marginal dollars.
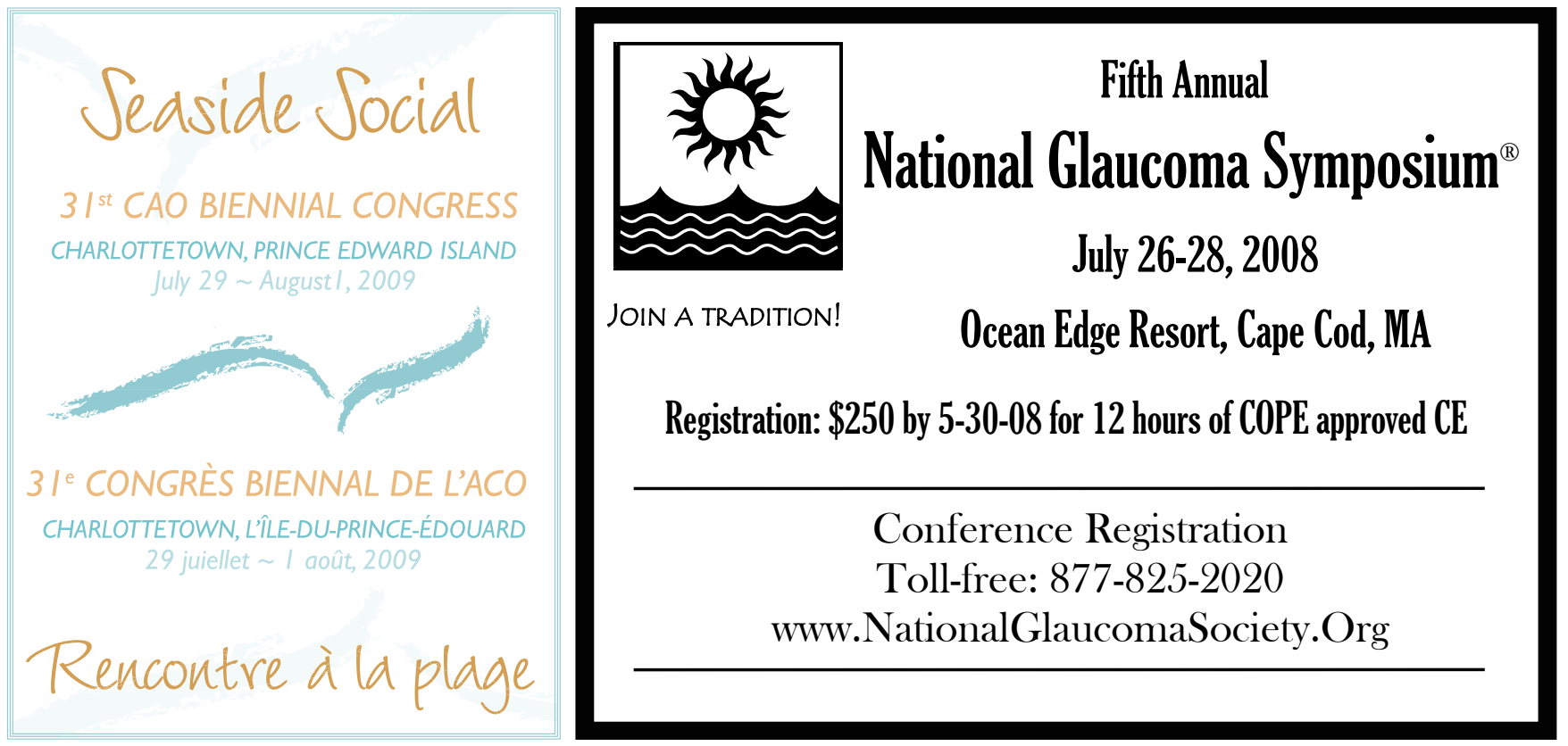